\title{
Activation of the Respiratory Burst Enzyme from Human Neutrophils in a Cell-free System Evidence for a Soluble Cofactor
}

Linda C. McPhail, Pamela S. Shirley, Christine C. Clayton, and Ralph Snyderman

Departments of Biochemistry and Medicine, Bowman Gray School of Medicine, Winston-Salem, North Carolina 27103; and the Laboratory of Immune Effector Function, Howard Hughes Medical Institute, Department of Medicine,

Duke University Medical Center, Durham, North Carolina 27710

\begin{abstract}
Activation of the respiratory burst in phagocytic cells, an important host defense process, is not yet well understood. We now report the development of a cell-free system for activation of NADPH oxidase, the respiratory burst enzyme, in human neutrophils. Activation was achieved by the addition of arachidonic acid to a postnuclear supernatant $(500 \mathrm{~g})$ from disrupted unstimulated cells (no arachidonate, 0.2 ; with arachidonate, $3.4 \mathrm{nmol}$ superoxide anion/min per $\mathrm{mg}$ ) and was dependent on both the concentration of arachidonate and on the amount of cellular material present. Activity stimulated by arachidonate appeared to be NADPH oxidase based on a Michaelis constant for NADPH of $32 \mu \mathrm{M}$ and a $\mathrm{pH}$ optimum of 7.0-7.5. Separation of the $500-g$ supernatant by high speed centrifugation revealed a requirement for both soluble and particulate cofactors. Activation of NADPH oxidase by arachidonate did not occur in the high speed pellet fraction from unstimulated cells but could be restored by the addition of the high speed supernatant. In addition, priming of intact neutrophils with low concentrations of the chemoattractant $\boldsymbol{N}$-formyl-methionyl-leucyl-phenylalanine or the tumor promoter phorbol myristate acetate replaced the soluble factor requirement for NADPH oxidase activation by arachidonate in the high speed pellet. This cell-free system can now be used to provide further insight into the biochemical basis of priming and the terminal mechanisms involved in the activation of NADPH oxidase.
\end{abstract}

\section{Introduction}

Critical to host defense mechanisms used by phagocytic cells is the enzymatic conversion of oxygen to several toxic metabolites, including superoxide anion $\left(\mathrm{O}_{2}^{-}\right)$and hydrogen peroxide (1). The enzyme system responsible for this respiratory burst

Portions of this work were presented at the Annual Meeting of the American Federation for Clinical Research, 4-7 May 1984, and were published in abstract form in 1984. Clin. Res. 32:315.

Address reprint requests to Dr. McPhail, Department of Biochemistry, Bowman Gray School of Medicine, Winston-Salem, NC 27103.

Received for publication 26 December 1984 and in revised form 29 January 1985.

J. Clin. Invest.

(C) The American Society for Clinical Investigation, Inc.

0021-9738/85/05/1735/05 $\$ 1.00$

Volume 75, May 1985, 1735-1739 appears to be an NADPH oxidase that is inactive until the cells have been stimulated by a wide variety of phagocytic, inflammatory, and surface-reactive agents $(1,2)$. The mechanisms that regulate the activation of this enzyme are not well understood. Recent evidence suggests, however, that in human polymorphonuclear leukocytes (PMNs) ${ }^{1}$ different classes of stimulating agents use separate multistep pathways that converge at a common intermediate $(3,4)$. Further, the shared pathway for oxidase activation can be modulated by sequential exposure of PMNs to certain combinations of heterologous stimuli or by prior exposure of cells to low concentrations of the same stimulus, a phenomenon known as priming $(4,5)$. Priming can occur in the absence of oxidase activation, resulting in potentiation of the activation rate and level of NADPH oxidase activated in response to the second stimulus. Based on these observations, we have proposed a two-stage model for stimulation of the respiratory burst that involves separate signals for priming and activation of NADPH oxidase (4).

Development of a cell-free system for oxidase activation would greatly facilitate progress in understanding the precise mechanisms that regulate this enzyme. Arachidonate and other long chain fatty acids have been shown to stimulate oxidative metabolism in intact human PMNs (6). Furthermore, observations made recently by Bromberg and Pick suggest that longchain fatty acids could activate NADPH-dependent $\mathrm{O}_{2}^{-}$production in disrupted inflammatory guinea pig macrophage preparations (7). We, therefore, tested the possibility that arachidonate could activate NADPH oxidase in a cell-free system from normal human peripheral blood PMNs and have also begun to define the role of priming in this system.

\section{Methods}

Isolation of PMNs. Human neutrophils of $>95 \%$ purity were isolated from heparinized venous blood by dextran sedimentation and FicollHypaque centrifugation $(3,4)$. After hypotonic lysis of contaminating erythrocytes, isolated cells were suspended in Hanks' balanced salt solution containing $10 \mathrm{mM}$ Hepes and $4.2 \mathrm{mM}$ sodium bicarbonate, pH 7.4 (HBSS; Gibco Laboratories, Grand Island, NY) at $\sim 1.5$ $\times 10^{8} / \mathrm{ml}$.

1. Abbreviations used in this paper: DMSO, dimethylsulfoxide; IMLP, $\mathrm{N}$-formyl-methionyl-leucyl-phenylalanine; PKC, protein kinase C; PMA, phorbol myristate acetate; $\mathrm{PMN}(\mathrm{s})$, human polymorphonuclear leukocyte(s). 
Fractionation of PMNs. Cells at $1 \times 10^{7} / \mathrm{ml}$ that had been kept at either $4^{\circ} \mathrm{C}$ or exposed to various agents at $37^{\circ} \mathrm{C}$ (see below) were centrifuged at $200 \mathrm{~g}$, resuspended in $0.34 \mathrm{M}$ sucrose to $5 \times 10^{7} / \mathrm{ml}$, and sonicated briefly as described previously $(3,4)$. Sonicates were centrifuged at $500 \mathrm{~g}$ to remove nuclei and unbroken cells, and an aliquot of the supernatant was saved. The remainder of this supernatant was recentrifuged at $48,000 \mathrm{~g}$ for $45 \mathrm{~min}$, the final supernatant was saved, and the final pellet (particulate fraction) was resuspended in a volume of $0.34-\mathrm{M}$ sucrose equal to the original volume centrifuged. In some experiments, as indicated, centrifugation at $100,000 \mathrm{~g}$ for 60 min was substituted. All fractions were assayed on the same day of isolation.

Priming of PMNs. Cells at $5 \times 10^{7} / \mathrm{ml}$ in HBSS were exposed to various agents at $37^{\circ} \mathrm{C}$ as described previously (4). Briefly, cells were prewarmed for $5 \mathrm{~min}$ in the presence of $1 \mathrm{mM}$ sodium azide (Sigma Chemical Co., St. Louis, MO) followed by the addition of either dimethylsulfoxide (DMSO; Sigma Chemical Co.) or the desired stimulus in DMSO. After a further incubation, the reaction was terminated by the addition of a fivefold excess of ice-cold HBSS. The priming agents tested were $N$-formyl-methionyl-leucyl-phenylalanine (fMLP) and phorbol myristate acetate (PMA), both of which were obtained from Sigma Chemical Co. Concentrations used and incubation times with the various agents are given in the legend to Table II. In some experiments, cytochalasin B (Sigma Chemical Co.) at $10^{-5} \mathrm{M}$ was also included and was added to the cells before the prewarm period.

NADPH oxidase assay. Activity was measured as the superoxide dismutase-inhibitable reduction of cytochrome $c$, exactly as described previously $(3,4)$, using either a Cary 219 or a Cary 2290 double-beam recording spectrophotometer (Varian Associates, Inc., Palo Alto, CA). Assay mixtures contained $0.1 \mathrm{M} \mathrm{K}_{\mathrm{x}} \mathrm{PO}_{4}, \mathrm{pH} 7.0 ; 0.08 \mathrm{mM}$ cytochrome $c$ (type III, Sigma Chemical Co.); arachidonic acid (Nu-Chek Prep., Inc., Elysian, $\mathrm{MN}$ ) prepared freshly in $25 \%$ ethanol (6) or $25 \%$ ethanol alone (final ethanol concentration, $0.6 \%$ ); and $0.1-1.0 \mathrm{mg} / \mathrm{ml}$ of cell fraction. The reaction was initiated by the addition of NADPH (Boehringer Mannheim Biochemicals, Indianapolis, IN), usually at 190 $\mu \mathrm{M}$, and initial rates were used for calculations. Activity was expressed as nanomoles of $\mathrm{O}_{2}^{-}$per minute per milligram of protein, using an extinction coefficient of $21 \mathrm{mM}^{-1} \mathrm{~cm}^{-1}(8)$. Protein was determined by the method of Lowry et al. (9). For Michaelis constant $\left(K_{\mathrm{m}}\right)$ determinations, concentrations of NADPH, ranging from 19 to 190 $\mu \mathrm{M}$, were used. Kinetic parameters were calculated by LineweaverBurk analysis.

In assays of xanthine oxidase-mediated $\mathrm{O}_{2}^{-}$generation, reaction mixtures were the same as those for assay of NADPH oxidase activity, except that xanthine $(0.5 \mathrm{mM}$; Sigma Chemical Co. $)$ and xanthine oxidase (grade I, $5 \times 10^{-3} \mathrm{U} /$ cuvette; Sigma Chemical Co.) were substituted for NADPH and cellular material.

\section{Results}

Arachidonate had a marked effect on NADPH-dependent $\mathrm{O}_{2}^{-}$ production by a postnuclear supernatant $(500 \mathrm{~g})$ from unstimulated PMNs. As shown in Fig. 1, neither the 500- $g$ supernatant nor $100 \mu \mathrm{M}$ arachidonate alone demonstrated $\mathrm{O}_{2}^{-}$-producing activity, either before or after the addition of NADPH. However, when the cell-free supernatant and arachidonate were mixed, a pronounced rate of $\mathrm{O}_{2}^{-}$generation occurred $(1.88 \mathrm{nmol} / \mathrm{min}$ per $\mathrm{mg}$ ) that depended on the presence of NADPH. In 15 experiments, activity (nanomoles of $\mathrm{O}_{2}^{-}$per minute per milligram; mean \pm SEM) in the absence or in the presence of 100 $\mu \mathrm{M}$ of arachidonate was $0.21 \pm 0.04$ and $3.39 \pm 0.37$, respectively. Activation by arachidonate in the $500-g$ supernatant was dependent on both the concentration of arachidonate and the amount of protein added (data not shown). Activity rose sharply as the arachidonate concentration was increased above $25 \mu \mathrm{M}$, peaked at $100 \mu \mathrm{M}$, and decayed at $160 \mu \mathrm{M}$. Arachidonate could activate $\mathrm{O}_{2}^{-}$production over a fivefold range of

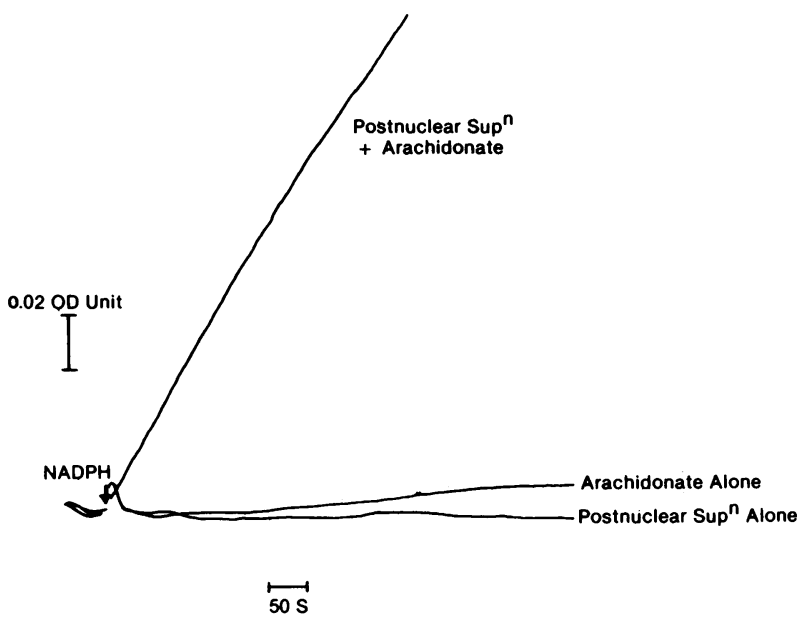

Figure 1. Activation by arachidonate of NADPH-dependent $\mathrm{O}_{2}^{-}$production in a 500- $g$ supernatant from unstimulated human neutrophils. Shown is a representative tracing of $\mathrm{O}_{2}^{-}$-producing activity measured in the presence of $0.4 \mathrm{mg} / \mathrm{ml}$ of a $500-\mathrm{g}$ supernatant obtained from disrupted unstimulated cells, $100 \mu \mathrm{M}$ arachidonate, or a mixture of the two. Assays were performed as described in Methods. Sup ${ }^{\mathrm{n}}$, supernatant.

protein concentration $(0.2-1.0 \mathrm{mg} / \mathrm{ml})$. Linearity was observed between $\sim 0.3$ and $0.6 \mathrm{mg} / \mathrm{ml}$.

It is possible that the arachidonate-mediated effect in the postnuclear supernatant $(500 \mathrm{~g})$ was caused by amplification of a free radical-mediated chain reaction initiated by normally undetectable levels of $\mathrm{O}_{2}^{-}$generation. This was tested by examining the effect of arachidonate on the xanthine-xanthine oxidase system. At a concentration of xanthine oxidase with a basal activity of $46 \mathrm{pmol} / \mathrm{min}$, arachidonate caused a twofold enhancement of $\mathrm{O}_{2}^{-}$production $(n=2)$. The basal activity of the postnuclear supernatant was $12.5 \pm 1.8 \mathrm{pmol} / \mathrm{min}$ (mean \pm SEM, $n=10$ ), and activity with arachidonate present was 15-fold greater. It, therefore, appears unlikely that arachidonate induces a free radical-mediated chain reaction of sufficient magnitude to account for the effects observed in the postnuclear supernatant.

It was important to determine if the NADPH-dependent $\mathrm{O}_{2}^{-}$-generating activity induced by arachidonate had characteristics similar to the "true" NADPH oxidase activity obtained by stimulation of intact neutrophils. Therefore, the $K_{\mathrm{m}}$ for NADPH and the pH optimum for the cell-free system were determined, and results are given in Fig. 2. A representative Lineweaver-Burk plot, yielding an apparent $K_{\mathrm{m}}$ of $35 \mu \mathrm{M}$, is shown in Fig. $2 \mathrm{~A}$. In a total of three experiments, the apparent $K_{\mathrm{m}}$ for the arachidonate activity was $32 \pm 4 \mu \mathrm{M}$, and the $V_{\max }$ was $4.6 \pm 1.2 \mathrm{nmol} \mathrm{O}_{2}^{-} / \mathrm{min}$ per $\mathrm{mg}(\operatorname{mean} \pm \mathrm{SEM})$. The $\mathrm{pH}$ optimum for the cell-free arachidonate-activated system is shown in Fig. 2 B. Optimal activity was observed between pH 7.0 and 7.5 .

The cell-free system was evaluated for the subcellular location of necessary cofactors. The postnuclear supernatant was fractionated by high speed centrifugation $(48,000 \mathrm{~g})$, and the supernatant and resuspended pellet were tested for arachidonate-induced NADPH oxidase activity. The data are summarized in Table I. Arachidonate increased NADPH oxidase activity in the unfractionated supernatant by 13 -fold. However, arachidonate had no activating effect in either the separated 

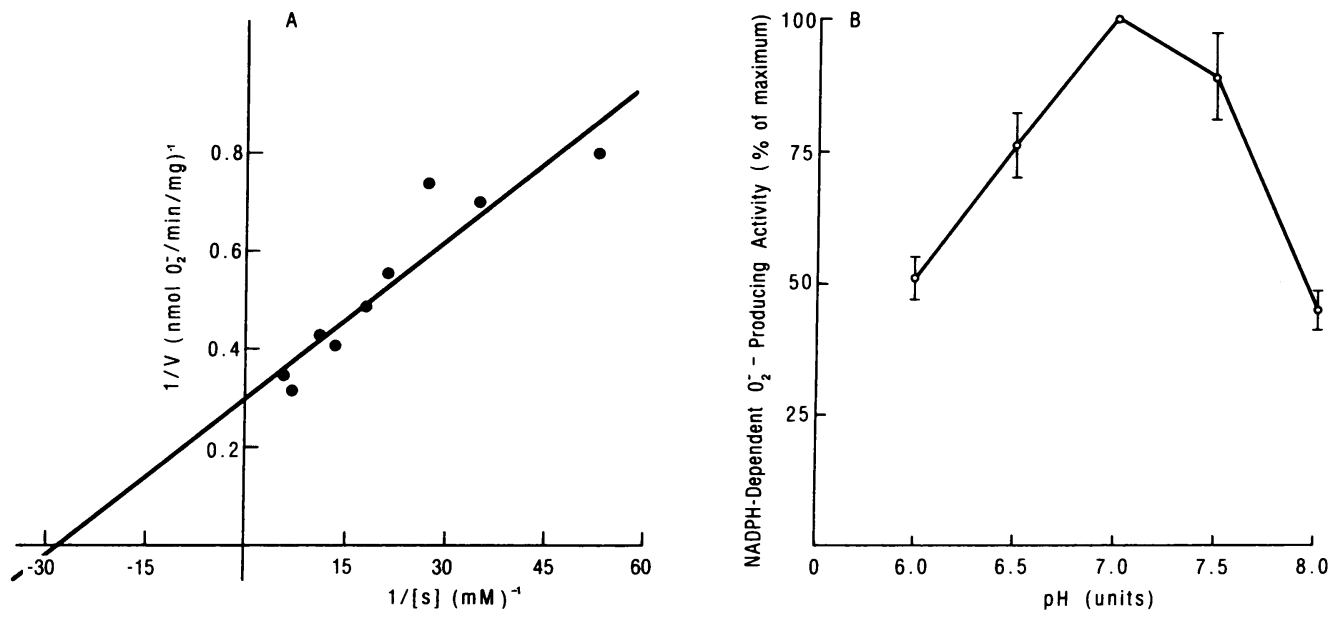

Figure 2. Characteristics of the cell-free NADPH-dependent $\mathrm{O}_{2}^{-}$-generating activity stimulated by arachidonate. $\mathrm{NADPH}$-dependent $\mathrm{O}_{2}^{-}$production was measured as described in Methods in the presence of $100 \mu \mathrm{M}$ arachidonate or with ethanol as a control using the 500- $g$ supernatant isolated from unstimulated PMNs. $(A)$ Lineweaver-Burk plot. Assays were performed in the presence of arachidonate at various NADPH concentrations. One experiment, representative of three performed, is shown. The line was drawn

by linear regression analysis with an $r$ value of 0.930 . The $K_{\mathrm{m}}$ and $V_{\max }$ values, in this experiment, were $35 \mu \mathrm{M}$ and $3.27 \mathrm{nmol} \mathrm{O}_{2}^{-} / \mathrm{min}$ per mg, respectively. $\mathrm{V}$, velocity; $\mathrm{S}$, substrate. $(B) \mathrm{pH}$ Optimum. Assays were performed in the presence of arachidonate or with $0.6 \%$ ethanol at the $\mathrm{pH}$ values indicated. Potassium phosphate buffers were used to achieve the desired $\mathrm{pH}$. Values shown have been corrected for any low level of activity observed with the ethanol control and are the mean \pm SEM of three experiments. Activity at $100 \%\left(\mathrm{pH}_{7.0}\right) \mathrm{was} 3.42 \pm 0.84 \mathrm{nmol} \mathrm{O}_{2}^{-} / \mathrm{min}^{2}$ per mg.

$48,000-g$ pellet or the 48,000-g supernatant. Reconstitution of the two high speed fractions restored the ability of arachidonate to activate, and the level of activity was much greater than the sum of the individual activities in the two separate fractions. To confirm the soluble nature of the supernatant factor, experiments were repeated using centrifugation at $100,000 \mathrm{~g}$ for $60 \mathrm{~min}$, and results were quite similar to those obtained at $48,000 \mathrm{~g}$ (data not shown, $n=4$ ). In Table I, the increase in activity over that seen in the absence of arachidonate in the reconstituted system (7.5-fold) was somewhat lower than that observed in the unfractionated, postnuclear supernatant. This was more apparent when specific activities of the unfractionated and reconstituted systems were compared $(2.47 \pm 0.15$ and

Table I. Effect of Subcellular Fractionation on the Cell-free Activation of NADPH Oxidase by Arachidonate

\begin{tabular}{|c|c|c|}
\hline \multirow[b]{2}{*}{ Cell fractionł } & \multicolumn{2}{|c|}{ NADPH oxidase activity* } \\
\hline & No arachidonate & With arachidonate \\
\hline Postnuclear supernatant & $10 \pm 2$ & $134 \pm 16$ \\
\hline $48,000-g$ pellet & $8 \pm 3$ & $6 \pm 3$ \\
\hline $48,000-g$ supernatant & $6 \pm 3$ & $6 \pm 3$ \\
\hline $\begin{array}{l}\text { Reconstituted pellet } \\
\text { plus supernatant }\end{array}$ & & \\
\hline$(48,000 \mathrm{~g})$ & $12 \pm 1$ & $90 \pm 13$ \\
\hline
\end{tabular}

* Activity was measured in the presence of $0.6 \%$ ethanol (no arachidonate) or in the presence of $100 \mu \mathrm{M}$ arachidonate (with arachidonate) and is expressed as picomoles of $\mathrm{O}_{2}^{-}$per minute. Values are given as the mean \pm SEM of four experiments, except that the number of experiments was 3 and 2, respectively, in the absence of arachidonate with the 48,000- $g$ pellet and the 48,000- $g$ supernatant. $¥$ Fractions were prepared from unstimulated neutrophils as described in Methods. Assay mixtures contained the following amounts of each fraction per cuvette: $20 \mu \mathrm{l}$ postnuclear supernatant; $20 \mu \mathrm{l} 48,000-g$ pellet; $40 \mu \mathrm{l} 48,000-g$ supernatant; or $20 \mu \mathrm{l}$ of $48,000-g$ pellet $+40 \mu \mathrm{l}$ of $48,000-g$ supernatant.
$1.03 \pm 0.25 \mathrm{nmol} \mathrm{O}-1$ min per $\mathrm{mg}$, respectively; $n=4$ ). Experiments are presently underway to optimize reconstitution conditions.

To explore further the mechanisms that regulate activation of NADPH oxidase, we tested the possibility that priming of neutrophils before subcellular fractionation would influence the response to arachidonate in the cell-free system. Results are given in Table II. Unstimulated neutrophils or neutrophils exposed at $37^{\circ} \mathrm{C}$ to DMSO or to priming concentrations of fMLP or PMA (4) were fractionated, and fractions were examined in the cell-free system. Activation by arachidonate was similar in the 500-g supernatants from all groups of cells. In agreement with results shown in Table I, arachidonate did not activate NADPH oxidase in the high speed pellet from unstimulated cells. However, arachidonate had a marked

Table II. Effect of Priming on Activation of NADPH Oxidase by Arachidonate in PMN Subcellular Fractions

\begin{tabular}{|c|c|c|c|c|}
\hline \multirow[b]{3}{*}{$\begin{array}{l}\text { Cell } \\
\text { treatmentł }\end{array}$} & \multicolumn{4}{|c|}{ NADPH oxidase activity* } \\
\hline & \multicolumn{2}{|c|}{$500-g$ supernatant } & \multicolumn{2}{|l|}{ High speed pellet } \\
\hline & $\begin{array}{l}\text { No } \\
\text { arachidonate }\end{array}$ & $\begin{array}{l}\text { With } \\
\text { arachidonate }\end{array}$ & $\begin{array}{l}\text { No } \\
\text { arachidonate }\end{array}$ & $\begin{array}{l}\text { With } \\
\text { arachidonate }\end{array}$ \\
\hline None & $0.17 \pm 0.03(8)$ & $2.44 \pm 0.55(8)$ & $0.10 \pm 0.04(6)$ & $0.21 \pm 0.04(6)$ \\
\hline DMSO & $0.17 \pm 0.07(4)$ & $1.32 \pm 0.32(4)$ & $0.16 \pm 0.07(4)$ & $1.62 \pm 0.48(4)$ \\
\hline fMLP & $0.50 \pm 0.19$ & $2.09 \pm 0.39$ & $0.07 \pm 0.04$ & $2.05 \pm 0.33$ \\
\hline PMA & $0.78 \pm 0.15(2)$ & $2.40 \pm 0.53$ & $1.49 \pm 0.42(2)$ & $4.79 \pm 0.58(2)$ \\
\hline
\end{tabular}

* Activity was measured in the presence of ethanol (no arachidonate) or in the presence of $100 \mu \mathrm{M}$ arachidonate (with arachidonate) and is expressed as nanomoles of $\mathrm{O}_{2}^{-}$per minute per milligram. Values are the mean $\pm \mathrm{SEM}$. The number of experiments is shown in parentheses.

‡ Fractions were isolated from neutrophils that were either unstimulated (none) or exposed at $37^{\circ} \mathrm{C}$ to the following: $0.1 \%$ DMSO for 5 or $15 \mathrm{~min}$ (2 experiments each); $10^{-8} \mathrm{M}$ fMLP for $30 \mathrm{~s}$ in the presence of $10^{-5} \mathrm{M}$ cytochalasin $\mathrm{B}$; or $3 \times 10^{-8} \mathrm{M}$ PMA for $15 \mathrm{~min}$. High speed centrifugation was performed at either $48,000 \mathrm{~g}$ for $45 \mathrm{~min}$ (none, 2; DMSO, 2; PMA, 2 experiments) or 100,000 $g$ for 60 min (none, 4; DMSO, 2; fMLP, 3 experiments). 
NADPH oxidase-activating effect in the high speed pellet isolated from either fMLP- or PMA-treated cells. Interestingly, activation was also observed in the high speed pellet from DMSO-treated cells. The highest activity was observed in the 48,000- $g$ pellet from cells exposed to PMA, although the fold increase was lower due to an elevated basal activity. No differences in these results were seen when the speed of centrifugation was $48,000 \mathrm{~g}$ or $100,000 \mathrm{~g}$. Arachidonate had no activating effect in the high speed supernatants from any group of PMNs (data not shown).

\section{Discussion}

Little is known of the mechanisms that regulate activation of NADPH oxidase, the respiratory burst enzyme, in phagocytic cells. Studies have been hampered by the necessity for manipulation of intact cells to influence enzyme activity. Such a requirement limits the use of inhibitors, which may not have accessibility to their target or may destroy cell viability, as well as complicates attempts to link stimulus-induced biochemical changes specifically with oxidase activation. We report here the development and initial characterization of a cell-free system for activation of NADPH oxidase. Arachidonate, a long chain unsaturated fatty acid that stimulates the production of $\mathrm{O}_{2}^{-}$by intact cells (6), caused activation of NADPHdependent $\mathrm{O}_{2}^{-}$production in a postnuclear supernatant $(500$ $g$ ) from unstimulated, noninflammatory human PMNs. This activity appeared to be NADPH oxidase, based on the apparent $K_{\mathrm{m}}$ of $32 \mu \mathrm{M}$ and the pH optimum of 7.0-7.5, values that are in close agreement with those reported for NADPH oxidase activity isolated from stimulated intact cells $(2,3)$. In addition, the results with the xanthine oxidase system for $\mathrm{O}_{2}^{-}$generation indicate that the effect of arachidonate could not be explained by a nonenzymatic enhancement of a free radical-mediated chain reaction. The level of NADPH oxidase activity induced by arachidonate is comparable to that achieved by stimulation of intact cells with chemoattractants or the calcium ionophore A23187 (3), stimulating agents that reportedly induce arachidonate release in neutrophils (10), and is about sixfold less than that observed with PMA (3).

These results are in agreement with those recently published by Bromberg and Pick (7), who used subcellular fractions from elicited guinea pig macrophages, and those of Heyneman and Vercauteren, who used horse PMNs (11), and extend their observations to the unstimulated normal human neutrophil. Activation by arachidonate in the macrophage preparation was not inhibited by the arachidonate metabolism inhibitors indomethacin and 5,8,11,14-eicosatetraynoic acid, and soybean lipoxygenase could not substitute for cellular material. It is likely, therefore, that an arachidonate metabolite is not responsible for activation in the cell-free system. In addition, Curnutte has recently made observations in human neutrophils that are similar to ours and has demonstrated that activation by arachidonate does not occur in subcellular fractions from PMNs of patients with chronic granulomatous disease (12, 13). These observations provide considerable support for the activation of NADPH oxidase by long chain unsaturated fatty acids in a cell-free system.

The studies reported here indicate that at least two factors, one soluble and one particulate, are involved in the pathway for NADPH oxidase activation (Table I). Similar results were obtained in the elicited macrophage (7) and in the nonelicited horse PMN (11), and the findings of Curnutte in the human neutrophil appear to agree with ours as well $(12,13)$. In addition, we have shown that priming of intact neutrophils induced a change in the cell's particulate fraction such that it became responsive to NADPH oxidase activation mediated by arachidonate. Possibly, the effect of priming is translocation of the soluble factor necessary for oxidase activation to the particulate fraction, and experiments to test this hypothesis are underway. The ability of arachidonate to activate in the neutrophil particulate fraction after priming is similar to the elicited macrophage system described by Bromberg and Pick (7). Thus, it is possible that the exposure of macrophages in vivo to an eliciting agent is analogous to the priming of neutrophils in vitro, and evidence for in vivo priming of neutrophils by elicitation to the peritoneum has been described (14). Alternatively, the macrophage may have somewhat different regulatory mechanisms for oxidase activation than those in the neutrophil.

The mechanism by which arachidonate activates NADPH oxidase is not yet clear. Possibly, the effects of arachidonate are mediated via protein kinase C (PKC), as suggested by our recent observation that arachidonate and other cis-unsaturated fatty acids can directly activate PKC in cytosolic fractions from human neutrophils (15). Further support for this concept is provided by other studies that suggest a role for PKC in the regulation of the respiratory burst in PMNs $(4,16-18)$. However, fatty acids are known to have a variety of effects in biological systems (19), and available evidence from the cellfree system is presently insufficient to implicate one mechanism over another. In conclusion, the cell-free system described here should be a valuable tool for further investigations into the biochemical basis of priming and the terminal steps of NADPH oxidase activation.

\section{Acknowledgments}

The excellent secretarial assistance of Ms. Deborah McLaughlin is gratefully acknowledged.

These studies were supported in part by U. S. Public Health Service grants AI-10732, CA-29589, and DE-08738.

\section{References}

1. Babior, B. M. 1978. Oxygen-dependent microbial killing by phagocytes. $N$. Engl. J. Med. 298:659-668.

2. McPhail, L. C., and R. Snyderman. 1984. Mechanisms of regulating the respiratory burst in leukocytes. In Regulation of Leukocyte Function. R. Snyderman, editor. Plenum Publishing Corp., New York. 247-281.

3. McPhail, L. C., and R. Snyderman. 1983. Activation of the respiratory burst enzyme in human polymorphonuclear leukocytes by chemoattractants and other soluble stimuli. Evidence that the same oxidase is activated by different transductional mechanisms. J. Clin. Invest. 72:192-200.

4. McPhail, L. C., C. C. Clayton, and R. Snyderman. 1984. The NADPH oxidase of human polymorphonuclear leukocytes. Evidence for regulation by multiple signals. J. Biol. Chem. 259:5768-5775.

5. Bender, J. G., L. C. McPhail, and D. E. Van Epps. 1983. Exposure of human neutrophils to chemotactic factors potentiates activation of the respiratory burst enzyme. J. Immunol. 130:23162323. 
6. Badwey, J. A., J. T. Curnutte, and M. L. Karnovsky. 1981. cisPolyunsaturated fatty acids induce high levels of superoxide production by human neutrophils. J. Biol. Chem. 256:12640-12643.

7. Bromberg, Y., and E. Pick. 1984. Unsaturated fatty acids stimulate NADPH-dependent superoxide production by cell-free system derived from macrophages. Cell. Immunol. 88:213-221.

8. Massey, V. 1959. The microstimulation of succinate and the extinction coefficient of cytochrome c. Biochim. Biophys. Acta. 34: 255-256.

9. Lowry, D. H., N. J. Rosebrough, A. L. Farr, and R. J. Randall. 1951. Protein measurements with the Folin phenol reagent. J. Biol. Chem. 193:265-275.

10. Takenawa, T., Y. Homma, and Y. Nagai. 1983. Role of $\mathrm{Ca}^{2+}$ in phosphatidylinositol response and arachidonic acid release in formylated tripeptide- or $\mathrm{Ca}^{2+}$ ionophore A23187-stimulated guinea pig neutrophils. J. Immunol. 130:2849-2855.

11. Heyneman, R. A., and R. E. Vercauteren. 1984. Activation of a NADPH oxidase from horse polymorphonuclear leukocytes in a cellfree system. J. Reticuloendothel. Soc. 36:751-759.

12. Curnutte, J. T. 1984. Activation of human neutrophil NADPH oxidase by arachidonic acid in a cell-free system. Blood. 64:66a.

13. Curnutte, J. J. 1985. Activation of human neutrophil nicotinamide adenine dinucleotide phosphate, reduced (triphosphopyridine nucleotide, reduced) oxidase by arachidonic acid in a cell-free system. J. Clin. Invest. 75:1740-1743.

14. Van Epps, D. E., and M. L. Garcia. 1980. Enhancement of neutrophil function as a result of prior exposure to chemotactic factor J. Clin. Invest. 66:167-175.

15. McPhail, L. C., C. C. Clayton, and R. Snyderman. 1984. A potential second messenger role for unsaturated fatty acids: activation of $\mathrm{Ca}^{2+}$-dependent protein kinase. Science (Wash. DC). 224:622-625.

16. Fujita, I., K. Irita, K. Takeshige, and S. Minakami. 1984 Diacylglycerol, 1-oleoyl-2-acetyl-glycerol, stimulates superoxide generation from human neutrophils. Biochem. Biophys. Res. Commun. 120: 318-324.

17. Penfield, A., and M. M. Dale. 1984. Synergism between A23187 and 1-oleoyl-2-acetyl-glycerol in superoxide production by human neutrophils. Biochem. Biophys. Res. Commun. 125:332-336.

18. Dewald, B., T. G. Payne, and M. Baggiolini. 1984. Activation of NADPH oxidase of human neutrophils. Potentiation of chemotactic peptide by a diacylglycerol. Biochem. Biophys. Res. Commun. 125: 367-373.

19. Badwey, J. A., J. T. Curnutte, J. M. Robinson, C. B. Berde, M. J. Karnovsky, and M. L. Karnovsky. 1984. Effects of free fatty acids on release of superoxide and on change of shape by human neutrophils: reversibility by albumin. J. Biol. Chem. 259:7870-7877. 